\title{
A comparison of creep, elasticity and strength of concrete in tension and in compression*
}

\author{
J. J. Brooks and A. M. Neville \\ Contribution by M. N. Haque \\ RMC, Duntroon, ACT, 2600 Australia
}

The paper by Dr Brooks and Professor Neville is very informative. On the strength development of concrete, they say that the "tensile and compressive strength exhibit similar characteristics under drying conditions". Table 1 of their paper shows that both the compressive and the tensile strength increased on air-drying. However, these findings on the tensile strength of concrete are not in complete agreement with those of Johnston ${ }^{(1)}$, Ward ${ }^{(2)}$ and Haque ${ }^{(3)}$, who observed a loss in the tensile strength of concrete on air- and oven-drying. The loss in tensile strength on drying has been attributed to microcracking, which is of critical importance in the determination of the tensile strength. Further, the concept of 'drying strengthening' does not seem to hold in the case of tensile strength of concrete, where strengthening effects of moisture removal are more than offset by the weakening effects of microcracking in the specimens.

\section{Reply by the authors}

Dr Haque's contribution is interesting and calls for a reply.

Although we stated that "tensile and compressive strengths exhibit similar characteristics under drying conditions", we also pointed out that the compressive strength shows an initial increase in strength when concrete is exposed to drying conditions, which is followed by a slower retrogression of strength, probably owing to the presence of shrinkage-induced microcracking (text on page 136 and Table 3 ). Therefore, our findings are not really at variance with those

\footnotetext{
* Pages 113 to 122 of $M C R 100$
}

It has been well documented that the modulus of elasticity of concrete decreases with increased drying and the results reported in the paper corroborate the earlier findings. Haque and $\operatorname{Cook}^{(4)}$ have also reported that the dynamic modulus of the concrete system decreases on desorption and attributed this to some irreversible changes in the structure of the hardened cement paste and to shrinkage-induced microcracking.

The observation by Dr Brooks and Professor Neville "that that tensile basic creep is mainly irreversible" was also reported by myself ${ }^{(5)}$ for the dessiccated sealed concrete specimens. This does establish the overriding importance of microcracking in the tensile creep of the concrete system. The authors' finding that "basic creep in tension is greater than basic creep in compression" can also be explained on the premises of microcracking as a dominant mechanism of tensile creep of concrete ${ }^{(5,6)}$.

reported in the references quoted by Dr Haque. The extent of microcracking, and hence the values of tensile and compressive strengths, must depend upon the rate of drying and upon the time when this occurs, viz. before or after the concrete has been loaded.

Regarding the role of microcracking in creep, we are of the opinion that, for compressive stressstrength ratios of $0 \cdot 3$, the contribution of microcracking to basic creep in compression is small. If microcracking were a predominant factor in basic creep of saturated concrete under compression, we would expect supporting evidence by way of a decrease in the modulus of elasticity and, in our tests, 
this was not the case. Likewise, for saturated concrete, the modulus of elasticity in tension did not decrease with age. It is because of the lack of such supporting evidence that we concluded that microcracking does not significantly contribute to basic creep in tension. Our findings are, strictly speaking, limited to the experiments performed, and we cannot say that the existence of extensive creep due to microcracking under other test conditions is precluded.

\section{REFERENCES}

1. JOHNSTON, C. D. Concrete and its constituent materials in uniaxial tension and compression. Thesis submitted to the Queens University of Belfast for the degree of PhD. 1967.

2. WARD, M. A. The testing of concrete materials by precisely controlled uniaxial tension. Thesis submitted to the University of London for the degree of PhD, 1964. pp. 312.

3. HAQUE, M. N. The effect of moisture content on the direct tensile strength of concrete cylinders and prisms. Proceedings, Sixth Australasian Conference on the Mechanics of Structures and Materials, University of Canterbury, Christchurch, New Zealand, August 1977. New Zealand, 1977. pp. 501-507.

4. HAQUE, M. N. and COOK, D. J. The effect of water sorption on the dynamic modulus of elasticity of desiccated concrete materials. Materials and Structures: Research and Testing. Vol. 9, No. 54. November-December 1976. pp. 407-410.

5. HAQUE, M. N. The tensile creep and strength of desiccated concrete and mortars. Thesis submitted to the University of New South Wales for the degree of PhD. 1974. pp. 228.

6. WARD, M. A. and CoOK, D. J. The mechanism of tensile creep in concrete. Magazine of Concrete Research. Vol. 21, No. 68. September 1969. pp. 151-158. 